\title{
Evaluasi Sistem Informasi Manajemen Kepegawaian dengan DS5 dan DS9 COBIT 4.1 Studi Kasus: Pemprov Bali
}

\author{
Laksmidewi, N.L.A ${ }^{1}$ Linawati $^{2}$, Widyantara, I.M.O. ${ }^{3}$
}

\begin{abstract}
The demands to implement interoperability of data between information systems, then before that it's required an evaluation to measure the performance of the system especially against employee information system. The standard used to evaluate is COBIT 4.1 framework, that is focused on Deliver and Support domain especially DS5 (Security System) and DS9 (Configuration Management). Evaluation of information systems based on questionnaire data where the determination of respondents refers to the RACI table. Questionnaires refers to the control practice DS5 and DS9 domains and processing using linkert scale. Employee information system evaluation results show that the percentage index achieved by each DS5 and DS9 subdomain averages above $66.66 \%$, and some of them get a percentage index between $33.33 \%-66.66 \%$. From the results of the assessment between groups of respondents showed various difference in scoring scores. The difference indicates that the objectives and benefits perceived by each respondent have not been align, which impact on the less optimal performance of the system. Therefore, to be able to improve the performance of information systems, the control points in the DS5 and DS9 domains that become priority in improving system performance are protection of security technology, sensitive data exchange system, repository and baseline configuration along with the identification and maintenance of the device configuration.
\end{abstract}

Intisari-Berkembangnya beragam sistem informasi backoffice serta adanya tuntutan untuk melaksanakan interoperabilitas data antar sistem informasi, maka sebelum itu perlu dilakukan evaluasi untuk mengukur kinerja sistem khususnya terhadap Sistem Informasi Manajemen Kepegawaian. Standarisasi yang digunakan dalam melakukan evaluasi adalah COBIT 4.1 framework yang difokuskan pada domain Deliver and Support khususnya DS5 (Keamanan Sistem) dan DS9 (Manajemen Konfigurasi). Evaluasi sistem informasi didasarkan pada data kuesioner dengan penentuan responden menggunakan tabel RACI. Kuesioner mengacu pada control practice domain DS5 dan DS9 yang diolah menggunakan skala linkert. Hasil evaluasi Sistem Informasi Kepegawaian menunjukkan bahwa indeks persentase yang dicapai oleh setiap subdomain DS5 dan DS9 rata-rata diatas $66,66 \%$, dan beberapa diantaranya memperoleh indeks persentase antara 33,33\%-66,66\%. Dari hasil penilaian antar kelompok responden menunjukkan selisih skor penilaian yang mengindikasikan bahwa belum selarasnya tujuan dan manfaat yang dirasakan oleh setiap responden yang berdampak pada kurang optimalnya kinerja sistem. Sehingga untuk dapat meningkatkan kinerja sistem informasi, maka poin kontrol dalam domain DS5 dan DS9 yang menjadi prioritas utama dalam meningkatkan kinerja sistem adalah perlindungan terhadap teknologi keamanan, sistem pertukaran data sensitif, konfigurasi repository dan baseline serta identifikasi dan

${ }^{1}$ Mahasiswa, Pasca Sarjana Jurusan Teknik Elektro Fakultas Teknik Universitas Udayana, Jln. Tegal Harum No.2 Biaung Kesiman Denpasar Bali 80237 INDONESIA (tlp: 081337181970; e-mail: aniek.laksmidw@gmail.com)

2, 3 Dosen, Pasca Sarjana Jurusan Teknik Elektro Fakultas Teknik Universitas Udayana, Jln. Panglima Besar Sudirman Denpasar Bali 80234 INDONESIA (telp: 0361-239599; fax: 0361239599; e-mail: linawati@unud.ac.id)

Laksmıaewı,IN.L.A.: Evaıuası sıstem InIorması ıvıanajemen ...
Teknologi informasi saat ini telah berkembang pesat dan telah menjadi bagian dalam menjalankan sistem pemerintahan, sebagaimana amanat yang tertuang dalam Instruksi Presiden Nomor 3 Tahun 2003 [1] dan Kebijakan dan Strategi Nasional Pengembangan e-Government oleh Kementerian Komunikasi dan Informasi Nomor: 55/KEP/M.KOMINFO/12/2003 Tahun 2003 [2]. Pada lampiran [1] diamanatkan juga bahwa implementasi tata kelola IT di lingkungan pemerintahan harus mendukung pelaksanaan interoperabilitas data antar sistem informasi, dimana interoperabilitas sistem informasi merupakan sebuah kemampuan untuk dapat saling berbagi pakai data antar sistem informasi.

Sebagai langkah tindaklanjut dari amanat [1] dan [2], Pemerintah Provinsi Bali telah mengembangkan berbagai sistem informasi untuk mendukung pelaksanaan tugas-tugas kedinasan sesuai dengan tugas masing-masing Organisasi Perangkat Daerah (OPD). Salah satunya adalah pengembangan sistem informasi manajemen kepegawaian (SIMPEG) yang merupakan sistem informasi yang mengelola data pegawai.

Sistem Informasi Manajemen Kepegawaian (SIMPEG) memuat data pegawai dari pertama kali diterima hingga pegawai tersebut pensiun. Data yang dimuat dan dihasilkan oleh sistem informasi ini bersifat internal dan dipergunakan untuk kepentingan OPD. Adanya tuntutan untuk melaksanakan interoperabilitas data serta berkembangnya berbagai sistem informasi back-office lainnya yang membutuhkan data pegawai maka perlu dilakukan evaluasi terhadap Sistem Informasi Manajemen Kepegawaian (SIMPEG).

Dalam melakukan evaluasi sistem informasi dibutuhkan sebuah standarisasi yang dapat mengevaluasi secara detail yaitu COBIT 4.1 Framework. Standarisasi COBIT 4.1 framework adalah standar kontrol yang umum digunakan pada teknologi informasi, dimana standar ini memberikan kerangka kerja dan kontrol terhadap teknologi informasi yang dapat diterima dan diterapkan secara internasional. COBIT 4.1 Framework terdiri dari 34 proses yang terbagi dalam 4 kelompok domain [3].

Berbagai penelitian terkait evaluasi sistem informasi dengan menggunakan COBIT 4.1 telah dilakukan oleh berbagai sumber. Pada [4] dilakukan evaluasi terhadap Sistem Informasi Manajemen Kepegawaian (SIMPEG) pada Kementerian Agama Kantor Kota Pekanbaru menggunakan framework COBIT 4.1 yang bertujuan untuk mengetahui dan mendeskripsikan kondisi pengelolaan IT, menilai kinerja menggunakan maturity level, menilai tingkat kesadaran pengelolaan (management awareness) dan menghasilkan suatu rekomendasi terhadap penerapan SIMPEG di Kemenag Kota Pekanbaru. Pada [5] dilakukan evaluasi sistem informasi yang secara dalam menganalisa kesesuaian layanan IT terhadap prioritas bisnis, optimalisasi biaya IT, pembuktian

$$
\text { p-ISSN:1693 - 2951; e-ISSN: 2503-2372 }
$$

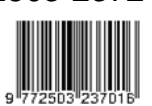


bahwa sistem dapat digunakan secara produktif dengan menggunakan COBIT yang berfokus pada domain Deliver and Support (DS). Pada [6] membahas tentang kondisi tata kelola sistem informasi kinerja pegawai SIKAP di BATAN khususnya pada kantor BATAN di Yogyakarta, dimana bertujuan untuk mengetahui sejauh mana penerapan tata kelola SIKAP di BATAN Yogyakarta yang berfokus pada 2 domain COBIT 4.1 yaitu PO dan ME. Pada [7] dilakukan audit tata kelola sistem informasi keuangan pada Universitas Kristen Duta Wacana (UKDW) menggunakan framework COBIT dengan domain DS dan ME terhadap layanan sistem informasi keuangan. Pada [8] dilakukan analisis audit penerapan sistem informasi manajemen keuangan daerah (SIMDA Keuangan) di Pemerintah Daerah Kabupaten Klungkung menggunakan kerangka kerja COBIT 4.1 domain PO (Plan and Organise) sub domain PO1, PO2, PO7 dan ITIL V3. Adapun tujuan untuk mengukur tingkat kematangan penerapan aplikasi SIMDA Keuangan didasarkan pada levellevel sasaran yang ditinjau dari kesiapan sumber daya manusia dan insfrastruktur Teknologi Informasi dan Komunikasi (TIK). Pada [9] dilakukan evaluasi penggunaan Sistem Informasi Akademik (SIAKAD) oleh manajemen dan user dengan menggunakan COBIT Framework 4.1 yang berfokus pada domain DS3, DS5 dan DS7 sehingga dengan evaluasi ini diharapkan SIAKAD dapat memberikan pelayanan informasi yang lebih cepat dan lebih baik, serta peningkatan dalam kinerja dan kapasitas, keamanan sistem dan optimalisasi skill dari SDM. Pada [10] membahas mengenai perancangan IT Governance di Universitas Stikubank Semarang dengan berfokus pada dua domain yaitu DS dan ME. Pada [11] dilakukan audit terhadap Sistem Informasi Akademik pada PT XYZ guna meningkatkan pengelolaan data akademik yang berfokus pada Domain Deliver and Support berdasarkan framework COBIT 4.1. Pada [12] dilakukan analisis pemanfaatan internet pada Dinas Perijinan Kota Denpasar dengan melihat karakteristik trafik, user behavior, serta besarnya bandwidth yang digunakan. Pada [13] dilakukan evaluasi tingkat kematangan interoperabilitas sistem informasi di lingkungan Ditjen Aptika dengan menggunakan metode evaluasi ISIMM dan analisa kesenjangan dimana hasilnya adalah rekomendasi untuk meningkatkan interoperabilitas sistem informasi sebagaimana yang diharapkan di lingkungan Ditjen Aptika yang disusun berdasarkan hasil evaluasi. Pada [14] dilakukan pengukuran tingkat kematangan sistem otomasi perpustakaan UIN SUSKA Riau dengan COBIT 4.1 yang memiliki fokus terhadap domain Deliver and Support pada proses Mengelola Kinerja dan Kapasitas (DS3).

Dalam rangka persiapan implementasi interoperabilitas antar sistem informasi, maka perlu dilakukan evaluasi Sistem Informasi Manajemen Kepegawaian (SIMPEG) untuk mengetahui kinerja sistem informasi saat ini serta hal-hal yang harus dioptimalkan sebelum dilaksanakannya interoperabilitas. Evaluasi tersebut menggunakan standarisasi COBIT 4.1 framework yang merupakan standarisasi umum yang sering digunakan dalam melakukan evaluasi sistem informasi. Keamanan dan kesuksesan transaksi data merupakan syarat utama dalam implementasi interoperabilitas antar sistem informasi, sehingga evaluasi sistem informasi menggunakan COBIT 4.1 ini difokuskan pada domain Deliver and Support khususnya DS5 (Memastikan Keamanan Sistem) dan DS9 (Manajemen Konfigurasi). Evaluasi sistem informasi ini nantinya menghasilkan poin-poin prioritas yang dapat dijadikan rekomendasi untuk meningkatkan kinerja Sistem Informasi Manajemen Kepegawaian (SIMPEG) khususnya pada keamanan sistem dan pengelolaan konfigurasi.

\section{IT GOVERNANCE}

IT Governance merupakan suatu struktur dari hubungan dan proses yang dapat menuntun suatu organisasi untuk mencapai tujuannya dan dengan memperhatikan resiko serta hasil yang diperoleh melalui pemanfaatan teknologi informasi. Terdapat 5 fokus utama dari area Tata Kelola TI antara lain: strategic alignment (penyelarasan strategis), value delivery (penyampaian nilai), resource management (pengelolaan sumber daya), risk management (pengelolaan resiko) dan performance measurement (pengukuran kinerja) [8].

\section{A. Sistem Informasi Manajemen Kepegawaian (SIMPEG)}

Sistem Informasi Manajemen Kepegawaian (SIMPEG) merupakan sistem informasi yang memuat detail data pegawai dari awal bekerja hingga pensiun termasuk data prestasi kinerja pegawai dan kenaikan pangkat/jabatan. SIMPEG berada dibawah pengelolaan Badan Kepegawaian Daerah Provinsi Bali dengan admin pengelola di masing-masing bidang sesuai tugas dan fungsinya. Sedangkan pengguna SIMPEG adalah OPD dan UPT di lingkungan Pemerintah Provinsi Bali dibawah koordinasi bidang/bagian kepegawaian dan di operasikan oleh satu orang operator yang ditugaskan oleh OPD bersangkutan.

\section{B. Evaluasi Sistem Informasi}

Evaluasi merupakan sebuah proses sistematis yang melakukan kegiatan pengumpulan dan evaluasi bukti secara objektif mengenai pertanyaan yang berkaitan dengan tindakan atau kejadian, membandingkannya dengan kriteria yang telah ditetapkan, serta menginformasikan hasilnya pada pihak yang berkepentingan sebagai bahan evaluasi dan pengembangan selanjutnya [5].

\section{COBIT 4.1}

COBIT (Control Objectives for Information and Related Technology) merupakan sebuah kerangka tata kelola TI atau dapat digambarkan sebagai sebuah alat yang memiliki fungsi untuk menjembatani gap yang terjadi antara kebutuhan dan teknis pelaksanaan dalam suatu organisasi [8]. COBIT 4.1 terdiri dari 34 proses yang terbagi dalam empat domain yaitu Plan and Organize (PO), Acquisition and Implementation (AI), Delivery and Support (DS) dan Monitoring and Evaluate (ME) [3]. Namun pada penelitian ini difokuskan pada domain DS khususnya DS5 dan DS9.

\section{Delivery and Support (DS)}

Domain Delivery and Support (DS) merupakan salah satu domain dalam COBIT 4.1 framework, dimana domain ini berkaitan dengan pengiriman aktual dari layanan yang 

dan kontinuitas, dukungan layanan bagi pengguna, dan manajemen data dan fasilitas operasional. Domain DS terdiri dari 13 domain proses [3] dimana salah satunya adalah DS5 (Keamanan Sistem) dan DS9 (Manajemen Konfigurasi). Setiap domain proses memiliki poin-poin kontrol dan kerangka kerja yang secara lebih detail dimuat dalam COBIT 4.1 Control Practises [15].

\section{E. Tabel RACI}

RACI merupakan singkatan dari Responsible, Accountable, Consulted dan Informed [3]. Tabel RACI menunjukkan siapa saja yang terlibat dalam suatu tindakan/pekerjaan dalam sebuah organisasi. Tabel RACI pada umumnya digunakan dalam manajemen resiko untuk lebih meningkatkan kinerja organisasi. Adapun peran dan fungsi yang terdapat dalam tabel RACI adalah sebagai berikut [17]:

- Responsible adalah orang yang melakukan suatu kegiatan atau melakukan pekerjaan.

- Accountable adalah orang yang bertanggungjawab dan memiliki otoritas untuk memutuskan sesuatu.

- Consulted adalah orang yang diperlukan untuk memberikan saran atau masukan dan berkontribusi terhadap kegiatan tersebut.

- Informed adalah orang yang harus mendapatkan informasi terkait kemajuan pekerjaan.

\section{Metode Penelitian}

Adapun tahapan dalam melakukan evaluasi Sistem Informasi Manajemen Kepegawaian (SIMPEG) adalah sebagai berikut.

\section{A. Pengumpulan Data}

Pengumpulan data dilakukan dengan mengumpulkan dokumentasi sistem informasi yang meliputi fitur, input/output, basis sistem informasi (desktop based atau web based), topologi jaringan dan proses bisnis sistem informasi. Pengumpulan data selanjutnya adalah pengumpulan data objektif melalui kuesioner dengan proses yang tidak jauh berbeda dengan penelitian [8]. Dimana pada penelitian ini, pengambilan data kuesioner berupa opini penilaian kinerja sistem informasi dilakukan dengan menggunakan control practise DS5 dan DS9.

\section{B. Penentuan Responden dan Penyusunan Kuesioner}

Penentuan responden pada penelitian ini dilakukan dengan mengacu pada tabel RACI (Responsible, Accountable, Consulted and/or Informed) COBIT 4.1, sebagaimana proses penentuan responden yang dilakukan pada penelitian [18]. Peran-peran yang didefinisikan dalam tabel RACI merupakan pemangku kepentingan yang terkait langsung pada proses DS5 dan DS9 yang kemudian dipetakan kepada peran-peran terkait yang terdapat dalam struktur organisasi Pemprov Bali terkait penggunaan SIMPEG. Adapun pemetaan responden kuesioner berdasarkan tabel RACI sebagaimana tercantum pada tabel I.

TABEL I

RESPONDEN KUESIONER SIMPEG BERDASARKAN RACI

\begin{tabular}{|l|c|c|c|}
\hline $\begin{array}{c}\text { Fungsional Struktur } \\
\text { COBIT 4.1 }\end{array}$ & $\begin{array}{c}\text { Fungsional Struktur } \\
\text { Pemprov Bali }\end{array}$ & RACI & Jumlah \\
\hline Head Development & $\begin{array}{c}\text { Kepala Bidang Data } \\
\text { dan Kedudukan } \\
\text { Hukum Pegawai }\end{array}$ & $\mathrm{A} / \mathrm{I}$ & 1 \\
\hline $\begin{array}{l}\text { Head IT } \\
\text { Administration }\end{array}$ & $\begin{array}{c}\text { Sub Bidang Data } \\
\text { Kepegawaian }\end{array}$ & $\mathrm{R} / \mathrm{C}$ & 1 \\
\hline $\begin{array}{l}\text { Compliance, audit, } \\
\text { risk and security }\end{array}$ & $\begin{array}{c}\text { Operator SIMPEG } \\
\text { pada OPD }\end{array}$ & $\mathrm{I}$ & 9 \\
\hline
\end{tabular}

Berdasarkan tabel I diatas, maka kuesioner dibuat ke dalam tiga model sesuai dengan tugas dan fungsi dari masing-masing responden yaitu kuesioner untuk penanggungjawab (Kepala Bidang Data dan Kedudukan Hukum Pegawai), kuesioner untuk pengelola (Sub Bidang Data Kepegawaian) dan pengguna (Operator SIMPEG pada OPD). Untuk responden pengguna mengambil sampel di 9 (sembilan) Biro yang ada di lingkungan Setda Provinsi Bali.

Setelah penentuan responden tersebut, maka dilakukan penyusunan kuesioner. Penyusunan pernyataan pada kuesioner mengacu pada control practise COBIT 4.1 domain proses DS5 dan DS9 [15] yang disesuaikan dengan lingkup tugas dan fungsi dari masing-masing kelompok responden. Penyusunan dan pengolahan kuesioner menggunakan skala linkert menggunakan tiga pilihan jawaban dengan skor masing-masing yaitu Ya (3), Tidak (2) dan Tidak Tahu (1) [16].

\section{Metode Pengolahan Data}

Pengolahan data terdiri dari pengolahan dokumentasi sistem informasi dan pengolahan kuesioner. Pengolahan kuesioner dilakukan pada setiap domain proses COBIT 4.1 yaitu DS5 dan DS9 dengan menggunakan skala linkert [16]. Pengolahan data kuesioner dilakukan dengan tahapan sebagai berikut:

1) Input Data Kuesioner: Melakukan input data kuesioner ke dalam bentuk numerik dengan mentranslasi terlebih dahulu jawaban responden sesuai dengan skor yang telah ditentukan yaitu: skor 3 untuk YA, skor 2 untuk TIDAK, skor 1 untuk Tidak Tahu.

2) Menghitung Skor Pernyataan : Melakukan perhitungan total skor masing-masing pernyataan dengan rumus

Total Skor $=(3 \times \mathrm{i})+(2 \times \mathrm{j})+(1 \times \mathrm{k})$

Persamaan rumus (1) diatas koefisien i mengacu pada intensitas jawaban $\mathrm{Ya}$, j mengacu pada intensitas jawaban Tidak dan k mengacu pada intensitas jawaban Tidak Tahu.

3) Menghitung Indeks Persentase : Setelah mendapatkan total skor masing-masing pernyataan maka dilakukan perhitungan indeks persentase dengan rumus

Indeks $\%=\frac{\text { Total Skor }}{\text { Skor Tertinggi }} \times 100$ 
Persamaan rumus (2) diatas dapat dijabarkan skor tertinggi adalah 3 dan total skor mengacu pada hasil yang didapatkan dengan menggunakan rumus (1).

4) Menghitung Indeks Persentase Domain Proses : Melakukan perhitungan indeks persentase domain proses DS5 dan DS9 dengan rumus

Indeks $\%$ domain proses $=\frac{\sum_{\mathrm{i}}^{\mathrm{j}} \text { indeks } \%}{\mathrm{n}}$

Persamaan rumus (3) diatas dapat dijabarkan bahwa i mengacu pada domain proses pertama pada satu domain, $\mathrm{j}$ mengacu pada domain proses terakhir pada satu domain sedangkan n mengacu pada jumlah domain proses dalam satu domain.

5) Menentukan Kriteria Interpretasi Skor: Menentukan kriteria interpretasi skor, dimana kriteria tersebut menginformasikan seberapa tingkatan implementasi domain COBIT 4.1 berdasarkan hasil pengolahan data kuesioner. Adapun penentuan kriteria tersebut dilakukan dengan menghitung interval skor persen terlebih dahulu menggunakan rumus

$\mathrm{I}=\frac{100}{\text { Jumlah Skor Linkert }}=\frac{100}{3}=33,33$

Sehingga dengan interval skor persen sebesar 33,33 maka kriteria interpretasi skor dapat ditentukan sebagai berikut :

$0 \%-33,33 \%=$ belum diimplementasikan

$33,34 \%-66,66 \%=$ dalam perencanaan implementasi

$66,67 \%-100,00 \%=$ sudah diimplementasikan

\section{Analisis Data dan Evaluasi SIMPEG}

Berdasarkan hasil pengolahan data tersebut dilakukan evaluasi SIMPEG untuk mengetahui kinerja sistem informasi saat ini serta hal-hal yang harus di optimasi sebelum pelaksanaan interoperabilitas data antar sistem informasi dengan mengacu pada COBIT 4.1 khususnya domain proses DS5 dan DS9.

\section{HASIL DAN PEMBAHASAN}

\section{A. Gambaran Sistem Informasi Kepegawaian (SIMPEG)}

Dalam era pengembangan teknologi yang mengarah pada digitalisasi telah memasuki sistem kerja pemerintahan yang mulai beranjak dari sistem kerja konvensional menuju sistem kerja digitalisasi. Pada era peralihan tersebut, beberapa SKPD mulai merancang dan membangun sistem informasi yang mengelektronikkan proses bisnis manual ke dalam sebuah aplikasi elektronik.

1) Proses Bisnis: Adapun bisnis proses dari aplikasi SIMPEG dapat dilihat pada Gambar 1 berikut.

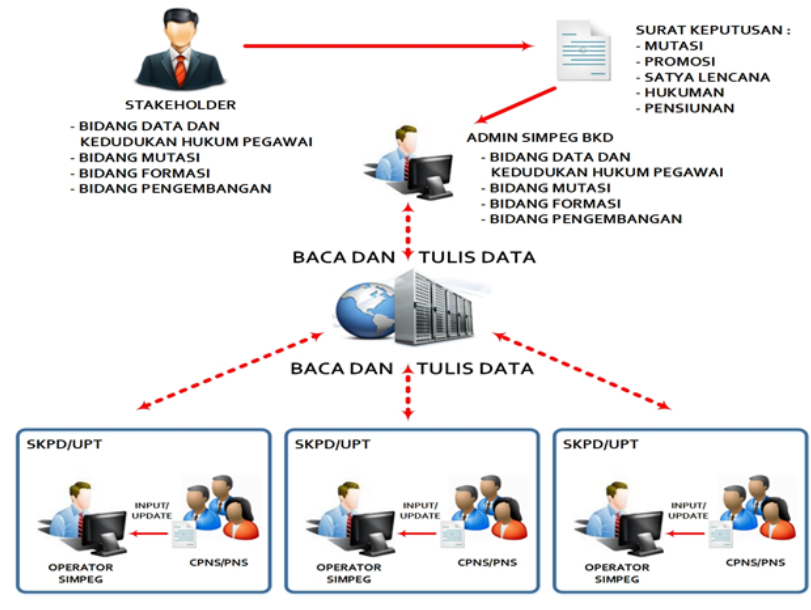

Gambar 1: Bisnis proses SIMPEG di Pemprov Bali

Seperti yang terlihat pada Gambar 1 diatas, disetiap SKPD/UPT terdapat operator SIMPEG yang bertugas untuk menginput dan mengupdate data kepegawaian di unit kerjanya. Untuk update data yang menyangkut history kepegawaian yang dimuat dalam surat keputusan seperti mutasi, promosi, satya lencana, hukuman dan pensiunan dilakukan oleh admin SIMPEG BKD berdasarkan surat keputusan yang dikeluarkan. Sedangkan update data lainnya dilakukan oleh operator masing-masing SKPD/UPT.

2) Arsitektur Jaringan: Arsitektur jaringan SIMPEG sudah tersentralisasi pada server SIMPEG yang ditempatkan pada Pusat Data Kantor Gubernur Bali. SIMPEG menggunakan sistem web-based sehingga untuk media akses pengguna ke server dibagi menjadi dua jalur akses yaitu jaringan intranet dengan memanfaatkan Jaringan Induk Pemprov Bali bagi SKPD/UPT yang berada di kawasan Renon (fiber optic) dan beberapa di luar kawasan Renon (radio wireless) dan jaringan internet untuk UPT yang berada di Kabupaten/Kota yang tidak terjangkau jaringan intranet. Untuk aksesnya dialokasikan IP lokal bagi jalur akses intranet dan IP publik untuk jalur akses internet. Adapun gambaran mengenai arsitektur jaringan SIMPEG dapat dilihat pada Gambar 2 berikut.

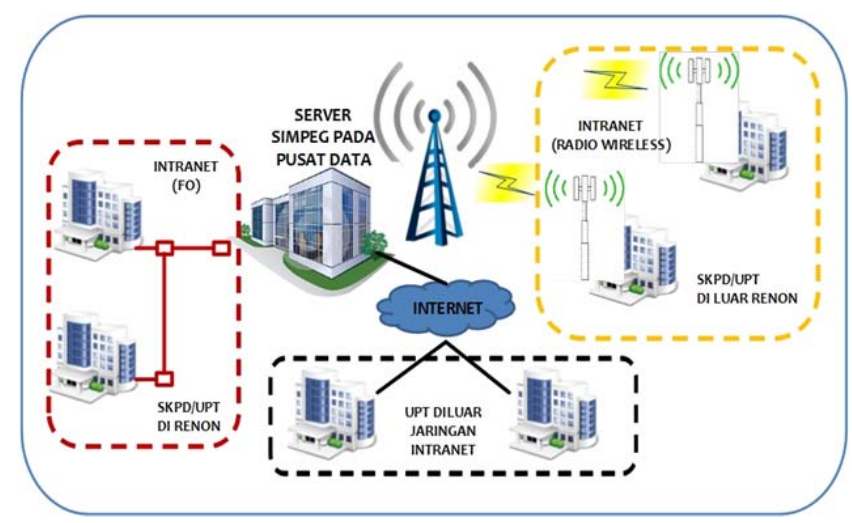


3) Arsitektur Aplikasi: Modul aplikasi SIMPEG terdiri dari pengguna dan pengelola, dimana pada level pengelola diberikan otoritas yang berbeda sesuai tupoksi antar bagian pada Badan Kepegawaian Daerah Provinsi Bali. Adapun arsitektur aplikasi SIMPEG adalah sebagai berikut :

- Jenis aplikasi : Web-based

- Bahasa program : Ruby 1.9.3

- Framework : Rails 3.1

- Database : MySQL 5.6

- JS Library : JQuery

4) Organisasi Pengguna: Organisasi pengguna SIMPEG terdiri dari SKPD/UPT di lingkungan Pemerintah Provinsi Bali dengan beberapa tingkatan otoritas pengguna, dimana BKD Provinsi Bali disamping pengguna juga merupakan pengelola SIMPEG dibawah Sub Bidang Data Kepegawaian. Adapun jumlah tingkatan pengguna yang diatur dalam SIMPEG dapat diilustrasikan seperti Gambar 3 berikut.

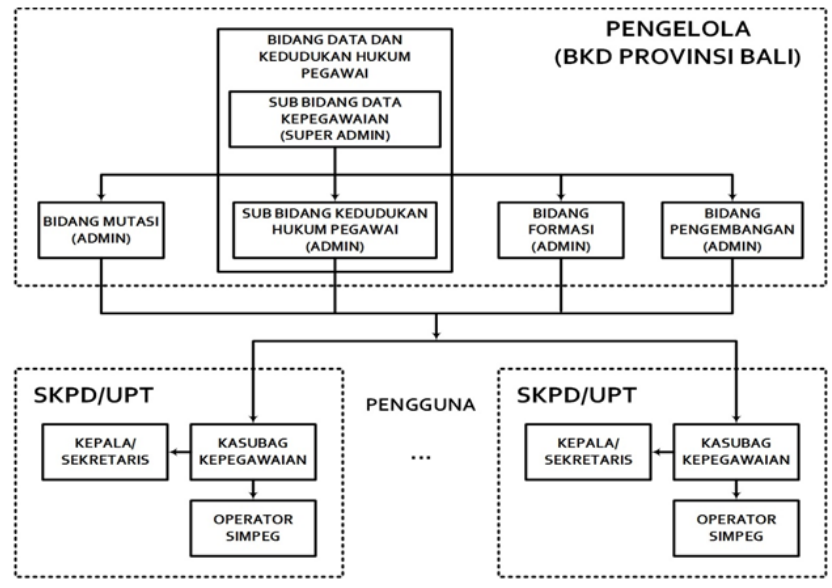

Gambar 3: Organisasi pengguna SIMPEG di Pemprov Bali

Berdasarkan gambar 3 diatas, dapat dijabarkan kewenangan masing-masing bagian organisasi pengguna tersebut yaitu sebagai berikut.

- Bidang Data dan Kedudukan Hukum Pegawai terdiri dari dua sub bagian. Sub Bidang Data Kepegawaian selaku Super Admin SIMPEG BKD mempunyai hak akses penuh. Sedangkan Sub Bidang Kedudukan Hukum Pegawai selaku Admin mempunyai hak akses pada melihat data dan laporan kepegawaian serta melakukan input terhadap pegawai yang telah pensiun dan meninggal dunia serta melakukan update data PNS yang mendapat hukuman disiplin.

- Bidang Mutasi selaku Admin mempunyai hak akses pada melihat data dan laporan kepegawaian serta melakukan update data riwayat kepangkatan pegawai.

- Bidang Formasi selaku Admin mempunyai hak akses pada melihat data dan laporan kepegawaian serta melakukan update data penghargaan satya lencana yang diterima pegawai.

- Bidang Pengembangan selaku Admin mempunyai hak akses pada melihat data dan laporan kepegawaian serta menggunakan fasilitas untuk kepentingan mutasi pejabat struktural serta fasilitas update data riwayat jabatan PNS yang memiliki jabatan fungsional.

- Pengguna terdiri dari 3 kelompok pengguna yang berada di setiap OPD/UPT. Kepala/Sekretaris Kepala pada OPD/UPT mempunyai hak akses hanya pada fungsi melihat data dan laporan kepegawaian SKPD yang berada di instansinya. Kasubag Kepegawaian mempunyai hak akses pada fungsi melihat data dan laporan kepegawaian pada SKPD yang bersangkutan serta melakukan update data PNS pada SKPD yang bersangkutan. Sedangkan Operator SIMPEG membantu pelaksanaan update data PNS dibawah pengawasan Kasubag Kepegawaian.

\section{B. Analisis Data dan Evaluasi SIMPEG}

Pengolahan data awal dilakukan dengan menganalisis dokumentasi Sistem Informasi Manajemen Kepegawaian (SIMPEG). Berdasarkan data tersebut, maka hasil analisis menunjukkan hal-hal sebagai berikut:

1) Bisnis Proses: Secara bisnis proses, SIMPEG sudah memenuhi kebutuhan minimal dari penyediaan informasi kepegawaian dan sudah sesuai dengan tugas dan fungsi dari BKD Provinsi Bali selaku leading sector pengelolaan data pegawai.

2) Arsitektur Jaringan: Secara arsitektur jaringan, SIMPEG telah memanfaatkan Infrastruktur Jaringan Induk Pemprov Bali dengan dukungan IP lokal dan IP Publik untuk dapat di akses secara internet maupun intranet.

3) Arsitektur Aplikasi: Secara arsitektur aplikasi, menggunakan ruby sebagai bahasa program, dimana bahasa program tersebut tidak banyak programmer yang menggunakannya. Akan tetapi, dari sisi sistem database nya menggunakan database yang umum dipergunakan yaitu MySQL. Dengan penggunaan sistem database MySQL ini, tentunya membuka peluang besar untuk dapat mengimplementasikan interoperabilitas dengan sistem informasi lainnya.

4) Organisasi Pengguna: Secara organisasi pengguna, SIMPEG telah menerapkan pembatasan hak akses dari setiap komponen organisasi pengguna sesuai dengan tugas dan fungsinya masing-masing.

Melalui analisis terhadap dokumentasi sistem informasi ini (SIMPEG), dapat memberikan gambaran pelaksanaan dan pengoperasian SIMPEG saat ini. Disamping itu juga, dengan mengetahui arstitektur aplikasi dapat memberikan gambaran terhadap data-data yang dapat di sharing atau data-data yang dibutuhkan dari sistem informasi lainnya.

Hasil analisis tersebut diatas, diperkuat kembali dengan pengolahan data kuesioner. Dari pengolahan data kuesioner ini, diperoleh penilaian kinerja SIMPEG berdasarkan opini yang diberikan pada pernyataan kuesioner. Pengolahan kuesioner dilakukan dengan menggunakan tahapan 
sebagaimana dijabarkan pada Bab III Metode Penelitian diatas. Dengan menggunakan persamaan rumus pada tahapan metode penelitian tersebut, maka hasil pengolahan data kuesioner adalah berupa indeks persentase setiap domain pada masingmasing kelompok responden sebagaimana pada Tabel II berikut.

TABEL II

INDEKS PERSENTASE DoMAIN DS5 DAN DS9 PADA SIMPEG

\begin{tabular}{|l|c|c|c|}
\hline Domain & Pengelola & Penanggungjawab & Pengguna \\
\hline DS5 & $\mathbf{6 2 , 5 0 \%}$ & $\mathbf{7 7 , 0 7 \%}$ & $\mathbf{7 8 , 7 9 \%}$ \\
\hline DS5.1 & $76,19 \%$ & $94,44 \%$ & $76,54 \%$ \\
\hline DS5.2 & $66,67 \%$ & $73,33 \%$ & $81,48 \%$ \\
\hline DS5.3 & $91,67 \%$ & $80,00 \%$ & $93,52 \%$ \\
\hline DS5.4 & $90,48 \%$ & $100,00 \%$ & $91,11 \%$ \\
\hline DS5.5 & $61,90 \%$ & $100,00 \%$ & $90,12 \%$ \\
\hline DS5.6 & $58,33 \%$ & $66,67 \%$ & $85,19 \%$ \\
\hline DS5.7 & $33,33 \%$ & $55,56 \%$ & $75,31 \%$ \\
\hline DS5.8 & $55,56 \%$ & $66,67 \%$ & $61,73 \%$ \\
\hline DS5.9 & $53,33 \%$ & $100,00 \%$ & $76,54 \%$ \\
\hline DS5.10 & $66,67 \%$ & $66,67 \%$ & $68,52 \%$ \\
\hline DS5.11 & $33,33 \%$ & $44,44 \%$ & $66,67 \%$ \\
\hline DS9 & $\mathbf{4 4 , 4 4 \%}$ & $\mathbf{7 9 , 6 3 \%}$ & $\mathbf{6 2 , 5 5 \%}$ \\
\hline DS9.1 & $33,33 \%$ & $55,56 \%$ & $53,70 \%$ \\
\hline DS9.2 & $33,33 \%$ & $83,33 \%$ & $64,81 \%$ \\
\hline DS9.3 & $66,67 \%$ & $100,00 \%$ & $69,14 \%$ \\
\hline
\end{tabular}

Berdasarkan indeks persentase yang dihasilkan sebagaimana Tabel II diatas, maka dapat diketahui bahwa sebagian besar subdomain proses pada setiap kelompok responden menghasilkan indeks persentase dengan skor diatas $66,66 \%$ dan beberapa diataranya mendapatkan skor antara 33,33\%-66,66\%. Disamping itu, ketahui juga bahwa penilaian kelompok responden terhadap masing-masing subdomain proses bervariasi dan banyak terdapat selisih skor penilaian antar kelompok responden. Untuk dapat melihat lebih jelas perbedaan penilaian tersebut dapat dilihat pada gambar 4 berikut.

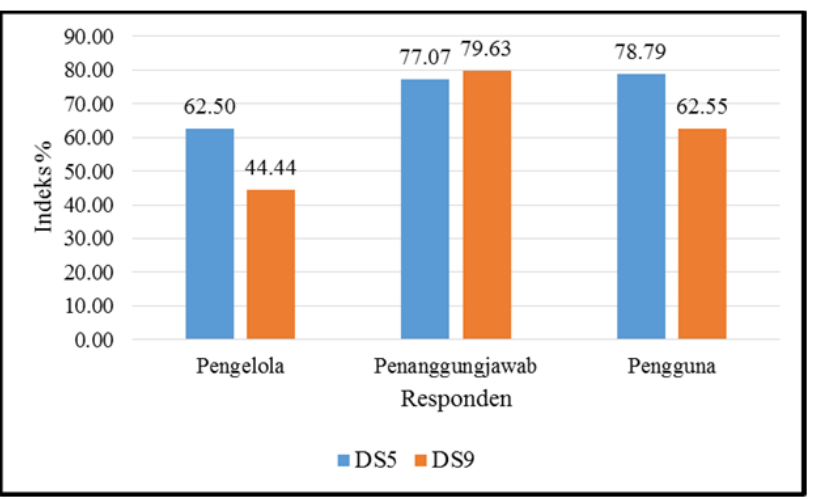

Gambar 4: Hasil penilaian responden kuesioner SIMPEG

Berdasarkan gambar 4 diatas, dapat dilihat bahwa penilaian pengelola terhadap SIMPEG melalui poin kontrol dalam DS5 dan DS9 lebih rendah dibandingkan penilaian penanggungjawab dan pengguna. Apabila dikaitkan dengan tugas dan fungsi dari setiap responden, penilaian pengelola terpusat pada penilaian SIMPEG secara teknis aplikasi, penilaian penanggungjawab lebih kepada regulasi dan kebijakan pelaksanaan SIMPEG dan penilaian pengguna mencerminkan pelayanan yang mampu diberikan oleh SIMPEG dalam memenuhi kebutuhan informasi kepegawaian. Sehingga dengan rendahnya hasil penilaian pengelola terhadap SIMPEG berdasarkan DS5 dan DS9, menunjukkan bahwa masih diperlukannya pengembangan dan optimasi secara teknis terhadap poin-poin yang menjadi cakupan dalam DS5 (Keamanan Sistem) dan DS9 (Manajemen Konfigurasi). Disamping itu, hasil penilaian penanggungjawab terhadap SIMPEG menunjukkan skor yang cukup baik. Akan tetapi untuk dapat lebih mendukung pelaksanaan teknis, perlu diimbangi dengan melakukan kajian kembali dengan tujuan untuk mengoptimasi regulasi dan kebijakan pelaksanaan SIMPEG. Sehingga dengan adanya dukungan regulasi dan kebijakan pada pelaksanaan pengembangan dan optimasi teknis terhadap SIMPEG, secara tidak langsung akan dapat meningkatkan penilaian pengguna dilihat dari peningkatan layanan yang dilaksanakan.

Poin-poin yang menjadi prioritas dalam pengembangan dan optimasi SIMPEG dengan merujuk pada penentuan kriteria interpretasi skor sebagaimana rumus (4) sebelumnya dikelompokkan dengan ketentuan sebagai berikut:

- Subdomain proses yang mendapatkan indeks persentase $33,33 \%$ kebawah perlu mendapatkan prioritas tinggi untuk dilakukan desain pengembangan dan implementasi (High).

- Subdomain proses dengan indeks persentase 33,34\% hingga $66,66 \%$ perlu dilakukan pengembangan dan optimasi (Medium).

- Subdomain proses yang mendapatkan indeks persentase $66,67 \%$ keatas masih diperlukan optimasi lanjutan untuk dapat mendukung peningkatan kinerja dan layanan SIMPEG (Low).

Sehingga dengan data sebagaimana Tabel II diatas dan kriteria interpretasi skor maka subdomain proses dari masingmasing kelompok responden dapat diurutkan berdasarkan prioritasnya sebagaimana Tabel III .

Pemilahan prioritas domain proses berdasarkan tabel III diatas dikelompokkan sesuai penilaian responden sehingga apabila dikelompokkan berdasarkan prioritasnya maka akan terdapat domain yang sama berada dalam prioritas yang sama. Akan tetapi lingkup sasaran pengembangannya masingmasing subdomain berbeda berdasarkan batasan kewenangan dari responden. Sehingga berdasarkan tabel III diatas, maka urutan subdomain yang mendapatkan prioritas dalam pengembangan dan optimasi adalah sebagai berikut :

- Prioritas high terdiri dari DS5.7, DS5.11, DS9.1 dan DS9.2 dalam lingkup teknis sistem informasi, regulasi dan kebijakan serta pelayanan kepada pengguna.

- Prioritas medium terdiri dari DS5.5, DS5.6, DS5.8 dan DS5.9 dalam lingkup regulasi dan kebijakan serta pelayanan informasi kepada pengguna. 
- Prioritas low terdiri dari DS5.1, DS5.2, DS5.3, DS5.4, DS5.10 dan DS9.3 dalam lingkup pelayanan informasi kepada pengguna.

TABEL III

PRIORITAS OptIMASI SUbDOMAIN PROSES PADA DS5 DAN DS9

\begin{tabular}{|l|l|l|l|}
\hline \multicolumn{1}{|c|}{ Responden } & \multicolumn{1}{|c|}{ High } & \multicolumn{1}{c|}{ Medium } & \multicolumn{1}{c|}{ Low } \\
\hline Pengelola & DS5.7, & DS5.5, & DS5.1, DS5.2, \\
& DS5.11, & DS5.6, & DS5.3, DS5.4, \\
DS9.1 & DS5.8, dan & dan DS9.3 \\
DS5.9 & \\
& DS9.2 & & \\
\hline Penanggungjawab & - & DS5.7, & DS5.1, DS5.2, \\
& & DS5.11, dan & DS5.3, DS5.4, \\
& & DS9.1 & DS5.5, DS5.6, \\
& & DS5.8, DS5.9, \\
& & & DS5.10, \\
& & & DS9.2 dan \\
& & DS9.3 \\
\hline Pengguna & - & DS5.8, & DS5.1, DS5.2, \\
& & DS9.1 dan & DS5.3, DS5.4, \\
& & DS9.2 & DS5.5, DS5.6, \\
& & DS5.7, DS5.9, \\
& & & DS5.10, \\
& & & DS5.11, \\
& & & DS5.11 dan \\
& & & DS9.3 \\
\hline
\end{tabular}

Terhadap subdomain proses yang dikelompokkan ke dalam prioritas high, apabila dilihat lebih detail poin-poin control practise [15], maka beberapa hal yang dapat menjadi rekomendasi teknis dalam mendesain pengembangan dan implementasi yang memiliki fokus pada teknis sistem informasi, regulasi dan kebijakan serta pelayanan kepada pengguna dalam rangka meningkatkan kinerja dan layanan SIMPEG adalah sebagai berikut:

- Perlindungan terhadap teknologi keamanan

- Pertukaran data sensitif

- Konfigurasi repository dan baseline

- Identifikasi dan pemeliharaan konfigurasi perangkat

Subdomain proses yang berada pada prioritas medium diperlukan langkah-langkah pengembangan dan optimasi oleh penanggungjawab selaku pemegang kewenangan dalam hal regulasi dan kebijakan serta pengelola selaku pemegang kewenangan teknis. Adapun hal-hal yang menjadi target pengembangan dan optimasi SIMPEG yang memiliki fokus pada regulasi dan kebijakan serta pelayanan informasi kepada pengguna adalah sebagai berikut:

- Uji keamanan, pengawasan dan pemantauan

- Definisi insiden keamanan

- Pengelolaan kunci kriptografi

- Pencegahan, pendeteksian dan perbaikan aplikasi berbahaya

Sedangkan subdomain proses yang berada pada prioritas low diperlukan langkah-langkah optimasi lanjutan oleh penanggungjawab dan pengelola dalam rangka meningkatkan layanan SIMPEG. Adapun hal-hal yang menjadi target dalam optimasi lanjutan terhadap pelayanan informasi kepada pengguna adalah sebagai berikut:

- Pengelolaan keamanan IT

- Perencanaan keamanan IT

- Identitas pengelola

- Pengelola akun pengguna

- Keamanan jaringan

- Analisis integritas konfigurasi

Prioritas pengembangan untuk meningkatkan kinerja dan layanan SIMPEG dalam rangka persiapan pelaksanaan interoperabilitas dilaksanakan berdasarkan subdomain proses yang berada pada prioritas high dan medium. Sedangkan domain proses lainnya yang berada pada prioritas low akan dilaksanakan optimasi lanjutan setelah dilakukan implementasi, pengembangan dan optimasi terhadap domain proses yang berada pada prioritas high dan medium. Sehingga dengan rekomendasi yang telah dipaparkan tersebut, dapat memberikan gambaran kepada penanggungjawab dan pengelola terhadap arah pengembangan dan implementasi dengan tujuan meningkatkan kinerja dan layanan SIMPEG dalam persiapan pelaksanaan interoperabilitas data antar sistem informasi.

\section{KESIMPULAN}

Hasil evaluasi SIMPEG berdasarkan pengolahan data kuesioner menunjukkan bahwa sebagian besar domain proses pada setiap kelompok responden menghasilkan indeks persentase dengan skor diatas 66,66\% dan beberapa diantaranya masih berada dibawah 66,66\%. Penilaian kelompok responden pada setiap domain proses terdapat selisih skor penilaian yang menunjukkan bahwa diperlukan optimasi dengan mengutamakan pengembangan domain proses yang berada pada prioritas high.

Domain proses yang berada pada prioritas high yaitu DS5.7, DS5.11, DS9.1 dan DS9.2. Sehingga berdasarkan domain tersebut, untuk meningkatkan kinerja dan layanan SIMPEG maka prioritas desain pengembangan dan implementasi terhadap teknis sistem informasi, regulasi dan kebijakan serta pelayanan kepada pengguna dititikberatkan pada perlindungan terhadap teknologi keamanan, sistem pertukaran data sensitif, konfigurasi repository dan baseline serta identifikasi dan pemeliharaan konfigurasi perangkat.

\section{REFERENSI}

[1] Instruksi Presiden Republik Indonesia.2003. Inpres Nomor 3 Tahun 2003 Tentang Kebijakan dan Strategi Nasional Pengembangan EGovernment. Jakarta: Republik Indonesia.

[2] Menteri Komunikasi dan Informasi.2003. Keputusan Menteri Komunikasi dan Informasi Nomor 55/KEP/M.KOMINFO/12/2003 Tentang Panduan Pengembangan Infrastruktur Portal Pemerintah. Jakarta: Republik Indonesia.

[3] IT Governance Institute. 2007. COBIT 4.1. USA: IT Governance Institute.

[4] Zulkarnaen, A., Anggraini. 2016. Evaluasi Sistem Informasi Manajemen Kepegawaian (SIMPEG) Menggunakan Framework COBIT 4.1 (Studi Kasus: Kementerian Agama Kantor Pekanbaru). Pekanbaru: Jurnal Rekayasa Dan Sistem Informasi,Vol.2,No 2, Agustus 2016. 
[5] Chaniago, M.B. 2016. Evaluasi Sistem Informasi Untuk Menilai Proses Deliver Dan Support Dalam Kegiatan Penelitian Dan Pengembangan Di Puslit Telimek LIPI. Bandung: Jurnal Ilmiah Teknologi Informasi Terapan Volume II, No.2, 15 April 2016.

[6] Sunardi, J., Winarno, W.W., Supriyono. 2015. Evaluasi Pengendalian Sistem Informasi Kinerja Pegawai BATAN (SIKAP) Menggunakan Framework COBIT 4.1. Yogyakarta: Jurnal PASTI Volume X No.1, Hal. 23-35.

[7] Ernawati, L., Santoso, H.B. 2016. Audit Tata Kelola Sistem Informasi Menggunakan Kerangka Kerja Control Objective for Information and Related Technology (COBIT). Yogyakarta: Seminar Nasional Teknologi Informasi dan Multimedia 2016 STMIK AMIKOM Yogyakarta.

[8] Pradnyana Jaya, P.A., Widyantara, I.M.O., Linawati. Audit Penerapan Aplikasi Sistem Keuangan Pemerintah Daerah Kabupaten Klungkung Menggunakan COBIT Domain PO dan ITIL. Denpasar: Teknologi Elektro Vol.16, No.1, Januari-April 2017.

[9] IAIN Raden Intan, MTI Institut Informatika dan Bisnis Darmajaya. 2015. Penggunaan Metode COBIT Framework 4.1 Dalam Mengaudit Sistem Informasi Akademik (SIAKAD) Pada IAIN Raden Intan Lampung. Jurnal TIM Darmajaya Vol. 01 No. 01 Mei 2015.

[10] Agus Prasetyo Utomo dan Novita Mariana. 2011. Analisis Tata Kelola Teknologi Informasi (IT Governance) pada Bidang Akademik dengan Cobit Frame Work Studi Kasus pada Universitas Stikubank Semarang Jurnal Teknologi Informasi DINAMIK Volume 16, No.2, Juli 2011.

[11] Satyareni, D.H., Mahanani, F. 2014. Audit Sistem Informasi Akademik Perguruan Tinggi (PT) XYZ Menggunakan Kerangka Kerja COBIT 4.1. Yogyakarta: Seminar Nasional Aplikasi Teknologi Informasi (SNATI).

[12] Surya Kencana, M.A., Linawati, Widyantara, I.M.O. 2016. Analisis Pemanfaatan Internet Di Pemerintah Kota Denpasar Studi Kasus: Dinas Perijinan. Denpasar: Teknologi Elektro Vo. 15, No. 2, JuliDesember 2016.

[13] Basuki, Agung. 2015. Evaluasi Kematangan Interoperabilitas Sistem Informasi Pemerintah: Studi Kasus Direktorat Jenderal Aplikasi Informatika Kementerian Komunikasi Dan Informatika (tesis). Jakarta: Universitas Indonesia.

[14] Megawati dan Surya Viddiany. 2015. Pengukuran Tingkat Kematangan Sistem Otomasi Menggunakan Maturity Model Pada Proses Mengelola Kinerja Dan Kapasitas (DS3) (Studi Kasus: Perpustakaan UIN SUSKA Riau). Riau: Jurnal Ilmiah Teknologi Informasi Terapan Volume I, No 2, 30 April 2015.

[15] IT Governance Institute. 2007. COBIT Control Practices 2nd Edition Guidance To Achieve Control Objectives For Successful IT Governance. USA: IT Governance Institute.

[16] Asra, A., Irawan, P.B., Purwoto,A. 2015. Metode Penelitian Survei. Jakarta: In Media.

[17] Kurniatiek, Y.D. dan Wijaya, A.F. Evaluasi Kinerja Teknologi Informasi Bagian Produksi Perusahaan Manufaktur Menggunakan Framework Cobit 4.1 (Studi Kasus: PT. XYZ, Ungaran). Salatiga: Fakultas Teknologi Informasi Universitas Kristen Satya Wacana.

[18] Zakwan, S., Ratnawati, S. dan Hidayah, N.A. 2014. Audit Tata Kelola Sumber Daya Teknologi Informasi Dengan Kerangka Kerja COBIT 4.1 Untuk Evaluasi Manajemen Pada Badan Pengawasan Keuangan Dan Pembangunan. Jakarta: Jurnal Sistem Informasi. 